\title{
Gestão do tempo e oportunidades de aprender na metrópole de São Paulo: uma análise de duas escolas situadas em territórios vulneráveis
}

\author{
Fernanda Marcucci* \\ Claudia Lemos Vóvio**

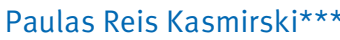

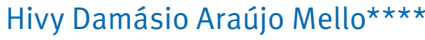

*(Universidade Federal de São Paulo

- Unifesp, Guarulhos-SP, Brasil)

**(Universidade Federal de São Paulo

- Unifesp, Guarulhos-SP, Brasil)

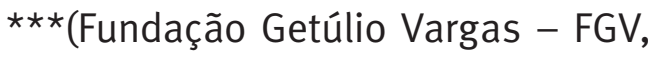
São Paulo-SP, Brasil)

$\star \star \star \star \star$ (Universidade Estadual de Campinas - Unicamp, Campinas-SP, Brasil)
Resumo: Analisa-se a arquitetura temporal de duas escolas públicas municipais paulistanas localizadas em território socialmente vulnerável, uma das facetas relativas à equidade na educação. 0 estudo qualitativo, com inspiração etnográfica, focalizou turmas de $3^{0}$ ano do Ensino Fundamental dessas escolas. Concentrou-se no manejo do tempo diante das determinações legais, especificamente naquele atribuído às aulas e ao ensino de língua portuguesa. Os resultados indicam dissemelhanças perante 0 estabelecido por essa rede municipal de ensino, o que denota desigualdade na distribuição de oportunidades educativas. Tendo em vista o que a literatura aponta sobre a distribuição de conhecimento escolar, em que alunos provenientes de meios mais desfavorecidos possuem desvantagens, a gestão do tempo tende a ser fundamental tanto na distribuição de oportunidades para todos realizarem aprendizados estabelecidos quanto no enfrentamento das desigualdades educacionais, que reproduzem desigualdades socioespaciais.

Palavras-chave: Gestão do tempo. Educação em territórios vulneráveis. Oportunidades educacionais. Equidade. 
INTRODUÇÃO

Em escolas localizadas em territórios socialmente vulneráveis ${ }^{1}$, várias pesquisas $^{2}$ indicam constrangimentos específicos que interferem no cumprimento de três funções essenciais da educação escolar: a função educativa, de promover o acesso e o compartilhamento de produções culturais, conhecimentos e valores; a de socialização, na sua face individual e social; e a distributiva, no sentido de integrar e prover qualificações que tenham valor social, principalmente na esfera do trabalho. No que toca à qualidade das oportunidades educacionais, para além do nível socioeconômico dos alunos, os estudos que se dedicam à análise das desigualdades socioespaciais observam os efeitos da sobreposição de desigualdades e do isolamento sociocultural sobre os processos educativos. Residir "em territórios pobres, isolados”, como aponta Sant'Anna (2009, p. 167), “contribui para que os indivíduos fiquem excluídos das principais correntes de influência da sociedade, vivenciando situações de fragilização social, tanto diante do mercado de trabalho, quanto diante da família, da escola e da moradia". A escola, nessas localidades, tende a ser um dos poucos braços do Estado, e teria, assim, papel ainda mais relevante no enfrentamento das desigualdades socioespaciais (ERNICA; BATISTA, 2012).

Este artigo aborda a gestão do tempo escolar atribuído ao ensino em escolas em territórios vulneráveis. Pressupõe-se que, para aprender algo, é necessário que se tenham oportunidades: dispor de tempo para o processo de ensinoaprendizagem torna-se essencial. As atribuições e usos do tempo escolar não são os únicos indicadores de que oportunidades de aprender ocorram, mas acredita-se que o cumprimento da carga horária estipulada por uma rede de ensino tende a ser uma condição básica. Essa condição, em escolas que atendem alunos desfavorecidos em termos de capital econômico, social e, sobretudo, cultural, merece atenção, já que a experiência escolar desses alunos, em termos ideais, deveria ser caracterizada mais por ganhos e avanços do que por faltas e correções, como explicado por Bourdieu (1998, p. 74) em

A vulnerabilidade social decorre de condicionantes sociais que se configuram de modo diferenciado em regiões e localidades de grandes metrópoles latino-americanas. Trata-se da impossibilidade de moradores de certas localidades, devido aos modos de ocupação e distribuição do solo urbano, de aproveitar as oportunidades socioeconômicas e culturais para melhorar sua situação de bem-estar, ou de agir para impedir que esta se deteriore ainda mais (KAZTMAN, 2001, p. 281).

Ver Kaztman (2001); Ribeiro (2008); Sant’Anna (2009); Ernica e Batista (2012), entre outros. 
relação à incorporação de capital cultural ${ }^{3}$ por esses grupos. Para a maior parte dos alunos que habita territórios socialmente vulneráveis, o aproveitamento do tempo escolar é fundamental para superar as desvantagens culturais oriundas da sua origem social e do local onde vivem, podendo denotar um tempo positivo ou negativo.

A percepção de variações na distribuição e na qualidade das oportunidades educacionais nessas localidades decorre da suposta quebra de expectativas diante do princípio de que os sistemas de ensino deveriam oferecer uma educação de base a todos, em resposta a exigências de ordem social. A Educação Básica - sobretudo a pública - deveria oferecer a todos condições similares para o desenvolvimento de capacidades e para a apropriação de conhecimentos, além de beneficiar igualmente os alunos com aprendizados e conteúdos socialmente valorizados. Porém, há variações significativas na oferta educacional para segmentos específicos da população, em especial residentes nas grandes metrópoles, em territórios de alta ou altíssima vulnerabilidade, conforme se pode apreender em estudos que utilizam avaliações estandardizadas ${ }^{4}$. No cerne dessa problemática encontramse algumas questões: as escolas pertencentes a um mesmo sistema de ensino, quando situadas em territórios socialmente vulneráveis, oferecem oportunidades de aprendizagem análogas para todos? Nessas localidades, a escola promove o desenvolvimento de níveis de aprendizado indicados nas metas estabelecidas para a Educação Básica, diminuindo o impacto da posição social de origem dos alunos no sucesso escolar? É possível, por meio da análise da gestão do tempo, identificar mecanismos geradores de desigualdades escolares, contribuindo para a proposição de dispositivos educativos mais igualitários e justos?

Os resultados apresentados neste artigo decorrem da pesquisa Interdependência competitiva entre escolas, realizada no extremo leste do município de São Paulo5. Um dos seus pressupostos é que situações de ensino e aprendizagem geradas no interior de uma mesma rede de ensino

3 o capital cultural está diretamente ligado à incorporação e assimilação, isto é, ao tempo de aquisição investido pelo indivíduo, tendo em conta não apenas o tempo de escolarização, mas a primeira educação familiar, dando-lhe "um valor positivo (de um tempo ganho, de um avanço) ou negativo (de um tempo perdido e, duplamente, uma vez que será necessário gastar tempo para corrigir seus efeitos), segundo a distância em relação às exigências do mercado escolar” (BOURDIEU, 1998, p. 74, grifos do autor).

Ver Ernica e Batista (2012) e Batista e Carvalho-Silva (2013).

Esta pesquisa é desenvolvida por meio de uma parceria entre o Centro de Estudos e Pesquisas em Educação, Cultura e Ação Comunitária (Cenpec), Unifesp e Universidade Cidade de São Paulo (Unicid). 
estariam cingidas por fatores externos e internos a cada unidade escolar, em grande medida, pela constituição e dinâmica do território onde se situa a escola, pela origem socioeconômica dos alunos e seus familiares (além do capital cultural), pelo clima acadêmico e gestão institucional, pelo conjunto de profissionais que nela atuam, não possuindo às vezes recursos e capacidades para o enfrentamento das desigualdades sociais (BOURDIEU, 1997; ERNICA; BATISTA, 2012; KAZTMAN, 2001; SANT'ANNA, 2009; SAMMONS, 2008; RIBEIRO, 2008). Como propõe Crahay (2002), é relevante reunir evidências empíricas que favoreçam o exame de fatores internos à escola e que ajam sobre o sucesso escolar de indivíduos das camadas mais desfavorecidas. De um lado, esses dados propiciam a compreensão sobre as questões externas que constrangem a escola e seus estudantes. De outro, indicam as possibilidades de a escola fazer a diferença em territórios socialmente vulneráveis e os fatores que concorrem para isso. É o caso dos estudos sobre o efeito-escola e o efeito-professor ${ }^{6}$ sistematizados por Bressoux (2003); sobre a eficácia escolar, organizados por Brooke e Soares (2008) e Sammons (2008); e sobre parâmetros que contribuem para tornar a escola justa, analisados por Crahay (2002) $)^{7}$.

No que se refere à gestão do tempo, tem-se como suposto que, para apropriarse de conhecimentos escolares e desenvolver capacidades, é preciso ter oportunidades. Em outras palavras, "os alunos só aprendem o que, de uma maneira ou de outra, lhes é dada a ocasião de aprender” (CRAHAY, 2002, p. 212, grifo nosso). Em contrapartida, não se pode esperar que alunos que não se beneficiam ou se beneficiam parcialmente de ocasiões para aprender atinjam níveis de proficiência adequados para o conjunto de escolas pertencentes a um mesmo sistema de ensino e estejam habilitados, como propõe Young (2014), a apropriarem-se de conhecimentos e criarem novos.

Considera-se ainda, como propõe Crahay (2002), que, no interior de sistemas de ensino pautados pela igualdade de oportunidades e de conteúdos, todos os alunos se beneficiariam de ocasiões análogas para apropriar-se de conhecimentos e desenvolver capacidades, especialmente as definidas nos documentos curriculares. A rede municipal de ensino de São Paulo (RMESP)

6 Por efeito-escola entende-se a possibilidade de uma unidade escolar fazer a diferença no aprendizado dos seus alunos devido a políticas, gestão institucional e práticas internas (BROOKE; SOARES, 2008).

Crahay (2002) organizou o estado da arte de estudos que tratam da relação entre o tempo e a aprendizagem dos alunos. Sammons (2008) sistematizou características de escolas que promovem um maior progresso de seus estudantes. Bressoux (2013) focaliza essencialmente o efeito-professor em escolas tomadas como eficazes. 
estabelece anualmente para todas as crianças o mesmo período de aulas, o mesmo quadro de horários e a mesma distribuição de disciplinas, definindo metas, objetivos e conteúdos comuns. A hipótese é que, dada a centralização da distribuição e uso do tempo nos processos de ensino e aprendizagem, os modos como escolhas e atribuições efetuam-se em escolas localizadas em território vulnerável podem gerar ganhos quando se maximiza o tempo, favorecendo mais ocasiões de aprendizagem, ou perdas, agindo de modo contrário na distribuição de bens tão fundamentais como são o conhecimento da linguagem escrita e seus usos sociais, opondo-se aos princípios de equidade e justiça escolar, multiplicando desigualdades no interior da escola (DUBET, 2008; RIBEIRO, V. M., 2012; MARCUCCI, 2015).

\section{O TEMPO DA/NA ESCOLA E A QUALIDADE DAS OPORTUNIDADES EDUCACIONAIS}

O tempo é um elemento bastante complexo e fundamental para a vida, como destaca Elias (1998, p. 14) ao analisar as diferentes relações com o tempo forjadas por distintas sociedades ao longo do processo civilizador:

\section{[...] o conceito de tempo não é objeto de uma aprendizagem, em sua simples qualidade de instrumento de uma reflexão destinada a encontrar seu resultado em tratados de filosofia; ao crescer, com efeito, toda criança vai se familiarizando com o "tempo" como símbolo de uma instituição social cujo caráter coercitivo ela experimenta desde cedo.}

Na escola, o tempo assume, assim, um estatuto fundamental. De um lado, constitui-se numa ordem que se aprende e se experimenta, regendo, desde cedo, os corpos, as atividades e as relações de equipes docentes, discentes, gestores e funcionários, além de familiares e comunidade escolar mais ampla. De outro lado, regulamenta e uniformiza a frequência, a jornada, a duração e a distribuição das etapas da escolarização.

Apesar de antiga, a ideia de uma escola para todos passou a ser tangível somente no século XIX e, em alguns países, como o Brasil, somente no século XX. Com o advento da escola de massa, que tem como exigência uma organização uniforme e racional, novas especificidades foram colocadas, especialmente a de educar muitos alunos concomitantemente. A noção de tempo na educação está diretamente ligada ao que compreendemos por forma escolar, e na instituição escolar, o tempo é elemento constitutivo de sua forma, como apontam Vincent, Lahire e Thin (2001, p. 13).

Numa organização pautada pela simultaneidade do ensino, pela graduação escolar, pela reunião de várias salas em um mesmo edifício e pela constituição 
de sistemas de ensino, o emprego do tempo torna-se correlato à vida escolar, sendo componente fundamental na história dessa instituição (ESCOLANO, 1993). O tempo escolar transcende os limites dessa instituição e modifica a vida cotidiana, especialmente a das crianças e jovens: o calendário escolar impõe-se aos costumes e ordena temporalmente a vida social (SACRISTÁN, 2005; VIÑAO FRAGO, 1997. Como afirma Sacristán (2005, p. 149), “o ano letivo escolar, equivalente ao ano escolar e ao curso, como unidade curricular, é um marcador decisivo da experiência da vida dos alunos, das famílias e até da atividade do comércio", comandando o mercado editorial e de produção de materiais escolares, o que denota sua importância não só na escola, mas em outras esferas da vida social. Nesse sentido, Escolano (1993) afirma que os alunos estão orientados pelo tempo da instituição escolar tanto no que tange ao comportamento visível como em termos biológicos e psicossociais, no corpo e no biorritmo, ajustando-os pela determinação de horários de alimentação, de descanso, de movimentação, etc., e na autorregulação de comportamentos da infância, tais como atenção e disciplina.

0 estabelecimento da arquitetura temporal da escola ${ }^{8}$ sustenta toda organização pedagógica: o estabelecimento de níveis e da classificação dos alunos, os programas e currículos escolares, a distribuição de períodos letivos e de férias, das aulas, tarefas, recreação e alimentação, entre outros. A principal materialização dessa organização encontra-se no calendário escolar e nos quadros de horários estabelecidos oficialmente, constituindo-se como instrumento regulador e de controle de professores e alunos e de visibilidade das práticas pedagógicas (VIÑAO FRAGO, 1997).

Assim, o estudo da gestão do tempo torna-se importante para analisar a qualidade das oportunidades educacionais em escolas situadas em territórios vulneráveis, visto que é um elemento que pode afetar o processo de ensino e aprendizagem dos estudantes. Pesquisas como as de Carroll (1984), Crahay (2002), Sammons (2008), Martinic, Vergara e Huepe (2013) e Martinic (2015) demonstram que há uma relação positiva entre a administração do tempo escolar e de aula pelo professor, a maximização do tempo efetivo de ensino e o desempenho dos estudantes. Nóvoa (1992, p. 27), ao discutir as características de escolas eficazes, aponta que "a otimização do tempo

Arquitetura temporal refere-se ao conjunto de marcadores temporais oficialmente delimitados, tais como organização curricular, calendário escolar e quadro de horários, que normatizam, regulam e sincronizam as atividades e práticas escolares, e ao resultado de operações realizadas no interior das escolas pelo conjunto de atores que podem gerar alterações, adaptações, transgressões e a reinvenção desses marcadores (TEIXEIRA, 1998). 
disponível é uma característica das escolas de qualidade”, que devem considerar também outros fatores nessa gestão, tais como "os ritmos próprios e o modo de organização interna de cada indivíduo”.

Devido ao papel atribuído ao tempo, como regulador do trabalho docente e da vida dos alunos e de controle da estrutura escolar, este passou a ser considerado na avaliação de sistemas de ensino e da eficácia escolar (MARTINIC; VERGARA; HUEPE, 2013; SAMMONS, 2008). Em países latinoamericanos, como o Chile, o Sistema de Avaliação de Desempenho Profissional do Ministério da Educação tomou como um dos critérios o emprego do tempo pelos professores, além da análise das interações em sala de aula, da relevância de conteúdos curriculares, da disciplina e do clima da aula. Estudos de Martinic, Vergara e Huepe (2013), que abarcaram as práticas pedagógicas de professores chilenos da Educação Básica, mostraram que a gestão do tempo conecta-se ao modo como se estruturam as aulas, atestando certos padrões em relação à distribuição do tempo para o ensino e ao estilo de interação dos professores. Constataram a prevalência de aulas altamente estruturadas com foco na exposição e transmissão de conhecimentos, que demandam atenção e muito tempo para a realização de tarefas pelos alunos, em detrimento de estratégias mais participativas e flexíveis. Notaram também que nas escolas de regiões periféricas há uma forte ênfase em aspectos disciplinares, com maior investimento de tempo para o controle de comportamentos dos alunos e menor para o processo de ensino e aprendizagem (MARTINIC; VERGARA; HUEPE, 2013, p. 132) ${ }^{9}$. Os autores concluíram que, geralmente, os docentes não empregam práticas pedagógicas inovadoras que considerem o ritmo de aprendizagem, as culturas e conhecimentos dos alunos, reproduzindo, em grande medida, a experiência escolar que tiveram.

Crahay (2002) organizou uma vigorosa revisão de pesquisas sobre o tempo atribuído à educação escolar e ao ensino e as consequências de sua gestão para o processo de ensino-aprendizagem e desempenho dos alunos, buscando evidências para propor um ensino mais justo e eficaz, pautado no princípio da igualdade de conhecimentos adquiridos ${ }^{10}$. Seu estudo organizase em duas vertentes. A primeira reúne pesquisas sobre o tempo atribuído às diferentes atividades escolares e à distribuição do tempo dedicado a cada

A pesquisa Talis indica que professores brasileiros declaram que empregam 19,8\% do tempo de aula para manter a disciplina (BRASIL, 2014).

10 O princípio baseia-se na justiça corretiva, visando à equidade educacional, em que o ensino estrutura-se de acordo com metas a serem atingidas por todos, implementandose dispositivos "para adaptar os recursos de ensino à sua diversidade" (CRAHAY, 2013, p. 29). 
uma das disciplinas escolares. A segunda enfoca os estudos que primaram por observar como se dá a gestão do tempo em termos da adequação entre o conteúdo focalizado e as oportunidades de aprendizagem.

Em relação à primeira vertente, guardadas as diferenças metodológicas, Crahay (2002) constatou uma forte variação no tempo atribuído ao ensino, seja entre escolas no interior de um mesmo sistema, seja entre turmas numa mesma escola. Em sistemas de ensino que tomam decisões mais centralizadas sobre o currículo, observa-se maior semelhança na distribuição e emprego do tempo do que naqueles descentralizados e intermédios, cujo emprego e distribuição do tempo apresentam índices de dissemelhança média ou elevada. A ideia de uniformidade, de que todas as escolas de um mesmo sistema poderiam ter todos os professores e alunos num mesmo ritmo, mostra-se impraticável e afirma o papel relativo da regulação do tempo: as prescrições oficiais influenciam só em parte a realidade das aulas.

Esses estudos indicam que a arquitetura temporal concentra-se em grande medida nas mãos dos professores, mas também está relacionada aos gestores e demais atores da comunidade escolar, sendo as recomendações oficiais suscetíveis de manipulação, em cada escola ou em cada turma. Viñao Frago (1997) corrobora a análise de Crahay (2002) ao sinalizar que o tempo, apesar de ser considerado elemento unitário, é um tempo cindido: o tempo oficial, regido por leis educacionais que interferem na gestão dos sistemas de ensino, e aquele que é praticado na escola, suscetível às condições objetivas em que o ensino se realiza, à manipulação do professor, dos alunos, dos gestores da escola e da comunidade mais ampla. É a partir da configuração dessa arquitetura que, potencialmente, podem-se identificar fontes de desigualdades no interior de sistemas e escolas.

Com base nos estudos da segunda vertente, Crahay constata a correlação positiva entre o tempo concedido ao ensino e o rendimento escolar: quanto maior é o tempo de ensino recebido, mais significativa tende a se tornar a aprendizagem. Mas pondera que não basta "utilizar o tempo escolar de forma óptima para ensinar saberes aos alunos” (CRAHAY, 2002, p. 290, grifo nosso), é preciso refletir sobre a qualidade das interações para fins de apropriação de conhecimentos, procedimentos e operações cognitivas.

Tanto Crahay (2002) como Martinic (2015) e Martinic, Vergara e Huepe (2013) consideram a maximização do tempo um fator importante na explicitação de desigualdades no interior de sistemas de ensino e escolas, mas reiteram: esse fator não explica o desempenho em sua totalidade, o que remete à 
complexidade do processo de ensino-aprendizagem e do conjunto de fatores nele implicados.

Com base nesses estudos, propôs-se a análise dos tempos escolares em turmas do 30 ano do Ensino Fundamental em duas escolas da RMESP localizadas em território socialmente vulnerável. A análise da arquitetura temporal produzida nas turmas do $3^{\text {ㅇ }}$ ano tem o intuito de identificar se há oportunidades para as crianças aprenderem conteúdos fundamentais do ciclo de alfabetização estabelecidos no currículo da RMESP. Longe de tramar modos de racionalizar o emprego do tempo, tomando a escola como organização social que desenvolve um sistema particular de relações entre atores, acredita-se, como propõem Bondioli e Mantovani (2002, p. 17), que “estudar o 'tempo' na escola significa [...] explorar, lançar uma sonda numa das dimensões educativas mais submersas, e dar início a uma reflexão livre de preconceitos sobre o emprego do tempo para fins educativos".

\section{MÉtodos e PROCEDIMENTOS DE ANÁLISE}

Dentre os diversos elementos que constituem as situações de ensino e aprendizagem na Educação Básica, baseamo-nos em estudos que enfatizam certas características como preditoras da eficácia da ação educativa, no sentido de fomentar a aprendizagem e o progresso dos alunos e, no caso em tela, de torná-los alfabetizados nos termos propostos pela RMESP. Esses estudos permitem formular a hipótese de que há correlação positiva entre a gestão do tempo de ensino e o aprendizado dos alunos (CRAHAY, 2002; SAMMONS, 2008; MARTINIC, 2015; MARTINIC; VERGARA; HUEPE, 2013).

Analisamos a arquitetura temporal em sete turmas de 30 ano do Ensino Fundamental (etapa de consolidação da alfabetização) de duas escolas localizadas em um mesmo território vulnerável e subprefeitura e pertencentes ao mesmo sistema de ensino. Para isso, utilizamos os relatórios de observação participante da escola e das aulas, produzidos no ano letivo de 2014 por uma equipe de pesquisadores bolsistas ${ }^{11}$, no interior da pesquisa já citada. As observações das aulas foram organizadas em três entradas simultâneas,

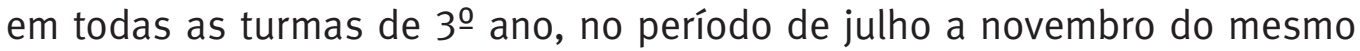

A pesquisa contou com equipe que elaborou instrumentos variados (questionários para os estudantes do $3^{0}$ ano e seus familiares/responsáveis, questionários e entrevistas semiestruturadas para os professores do $3^{\circ}$ ano e equipe de gestão, coleta documental de cadernos escolares e planos de aula do $3^{\circ}$ ano e de livros de ocorrência), planejou a entrada em campo, revisou bibliografia e previu procedimentos de análise, bem como de grupo pesquisadores bolsistas que coletaram os dados. 
ano, comportando, em média, 75 horas em cada turma. Em cada entrada, as turmas foram observadas ao longo da semana, por cinco dias consecutivos, para permitir avaliar a distribuição da carga horária das disciplinas e observar permanências e mudanças em torno da rotina diária escolar. É razoável esperar que a escola cumpra a carga horária de cada disciplina ao longo da semana e que, em dia específico, se observe, por exemplo, uma carga horária maior para certa disciplina ou até mesmo sua ausência.

Os registros das aulas foram orientados por meio de um protocolo com foco na rotina e no encadeamento de propostas e atividades diárias, contendo: a) horário de início e término da aula ${ }^{12}$; b) a descrição da rotina e distribuição de disciplinas; c) especificamente em língua portuguesa, atividades e dispositivos didáticos mobilizados (com indicação do tempo empregado para introduzir, desenvolver e concluí-las); d) registro do tempo diário de recreação, alimentação, de interrupções, pausas e descontinuidades no desenvolvimento das aulas; e) outros elementos. Os dados foram registrados em uma base construída especificamente para tal fim e tabulados. A análise concentrou-se na gestão do tempo vis-à-vis às determinações legais da RMESP (o tempo oficial que regula o currículo e as aulas), envolvendo, sobretudo, o modo como os docentes e demais atores da escola manipulam o tempo, de forma a abarcar os diversos eixos de conteúdo previstos no currículo de alfabetização. Essa gestão envolve diversos atores, desde funcionários e agentes escolares, passando pela equipe de direção, coordenação e docentes, até os próprios alunos, que, por vezes, interferem direta ou indiretamente nessa arquitetura temporal.

$\mathrm{Na}$ análise, distinguem-se as seguintes categorias:

- Tempo de permanência - compreende o tempo de permanência de um dia na escola, do momento da entrada ao da saída. Oficialmente, a abertura dos portões ocorre entre $6 \mathrm{~h} 50$ e $7 \mathrm{~h}$ para a entrada e às $12 \mathrm{~h}$ para a saída; são cinco horas diárias de permanência na escola, ou 300 minutos. Porém, o tempo de permanência efetivo pode ser diferente do tempo oficial.

- Tempo de refeição - abarca os momentos em que as crianças se alimentam (café da manhã e almoço). Assim como na categoria anterior, há o tempo oficial e o efetivo.

- Tempo morto - trata-se da soma de dois termos: o tempo com interrupções e a diferença entre o tempo de permanência oficial e o tempo de permanência efetivo. Em outras palavras, o tempo morto é

\footnotetext{
Cf. Matêncio (2001).
} 
um tempo que poderia ter sido gasto com atividades escolares, mas não o foi, por conta de eventos previsíveis na rotina, por imprevistos ou ainda porque os alunos não estavam da escola.

1. Interrupções (A): quaisquer eventos previstos que causam a descontinuidade de atividades em sala de aula, tais como o almoço e aulas de outros professores especialistas ${ }^{13}$.

2. Interrupções (B): eventos imprevistos que descontinuam atividades, como a entrada de pessoas no ambiente ou conflitos entre os alunos.

- Tempo dedicado ao ensino - é aquele em que os alunos estavam em sala de aula, excetuadas as interrupções: situações nas quais eles interagem com o professor a partir de atividades e propostas pedagógicas. Oficialmente, são 270 minutos, mas o tempo efetivo pode ser menor ou maior.

O foco da análise recai sobre o tempo dedicado ao ensino, isto é, as variações em relação ao tempo oficialmente consagrado e aquele de fato empregado para ensinar, buscando compreender as implicações de semelhanças ou dissemelhanças observadas. Tais variações podem ser resultantes de dinâmicas, processos e do conjunto de condições objetivas de organização e funcionamento de cada escola, um tempo institucional criado com e a partir dos atores envolvidos no processo educativo, dentro do qual se distribui e se enxerta a rotina diária. Em caso de dissemelhança, é possível tomá-la como indicador de desigualdade na distribuição de oportunidades para aprender ou no tratamento de conteúdos fundamentais para o sucesso escolar.

\section{CARACTERIzAÇÃo dA Escola A E dA Escola B B ${ }^{14}$}

As duas escolas foram selecionadas intencionalmente, dada a localização de ambas em um mesmo território, na mesma subprefeitura, distando entre si cerca de 2 quilômetros, e por atenderem alunos de nível socioeconômico semelhante. Ambas participaram deste estudo de modo colaborativo, acolhendo os pesquisadores em diferentes momentos do ano letivo, abrindo as portas para observação participante e assumindo compromissos quanto à identificação de dinâmicas e processos que poderiam ser aprimorados.

${ }_{13}$ Nos protocolos, uma atividade só era dada como terminada quando ocorria sua conclusão, conforme Matêncio (2001). Por exemplo, se a professora começasse uma atividade, a pausasse para que os alunos almoçassem e a concluísse após o almoço, o horário de término de tal atividade constaria como após o almoço, descontando-se o tempo do almoço.

${ }_{14}$ Omitiu-se a identidade das escolas para garantir o sigilo e o compromisso ético adotado.

cadernoscenpec | São Paulo | v.8 | n.2 | p.43-70 | jul./dez. 2018 
No momento da geração de dados, a Escola A contava com 1.212 alunos, divididos em três turnos: 450 alunos no período matutino, 455 no período vespertino e 307 no noturno. No período diurno, a unidade dispunha de 15 turmas de anos iniciais e 15 turmas de anos finais do Ensino Fundamental; e nove turmas de Educação de Jovens e Adultos (EJA) no noturno. Contava com 55 docentes, todos com formação em nível superior. 0 prédio escolar possuía 15 salas de aula, uma sala de leitura, laboratório de informática para alunos (com acesso à internet), pátio coberto e descoberto, quadra de esportes, sala de professores, secretaria, sala de diretoria e coordenação, almoxarifado e refeitório. Nos corredores de acesso às salas de aula, havia murais com trabalhos e atividades dos alunos. 0 mobiliário era praticamente novo e adequado para as atividades pedagógicas. Apesar de contarem com salas arejadas, equipadas e bem iluminadas, suas dimensões não favoreciam rearranjos diversos da organização em fileiras ou duplas para a realização de atividades. A escola se situa em área de vulnerabilidade média, com IPVS 4 $(\text { SEADE, 2015) })^{15}$.

Quanto ao desempenho, a Escola A apresentava proficiências em português e matemática inferiores à média das escolas municipais de São Paulo em 2011 ${ }^{16}$ : 178,22 e 196,94, respectivamente (INEP, 2015). No entanto, essa escola apresentou um crescimento da média de português, que, em 2007, era de 159,65 (aumento de 18,57 pontos), bem como uma leve queda na taxa de distorção idade-série do EF1, entre 2007 e 2014, passando de 6,2\% para $5,8 \%$. A taxa de reprovação para os anos iniciais do Ensino Fundamental foi, em 2014, de 5,6\% (QEdu, 2015). Em relação ao desempenho específico na alfabetização, na Avaliação Nacional de Alfabetização (ANA), em 2014, $86,11 \%$ dos alunos que frequentavam as quatro turmas de 30 ano realizaram a avaliação. Desses, 70,97\% encontravam-se no nível 4 em escrita. Já em leitura, a maior parte deles encontrava-se nos níveis 2 e 3: 22,58\% e 46,24\%, respectivamente ${ }^{17}$.

A Escola B, por sua vez, contava, à época da geração de dados, com 1.151 alunos também subdivididos em três turnos: 498 no período matutino, nos anos iniciais do Ensino Fundamental, 389 no período vespertino, nos anos finais, e 264 à noite, na EJA. Havia 17 turmas destinadas aos anos iniciais, 15 aos anos finais e dez à EJA. Possuía 18 salas de aula, sala de leitura,

15 A escala da Fundação Seade varia de 1 a 7 , sendo 7 a mais alta.

16 Na RMESP, a média de língua portuguesa, em 2011, era de 181,55 e a de matemática, $197,53$.

17 Há cinco níveis de proficiência na escala de escrita, sendo 1 o mais baixo e 5 o mais alto. Em leitura, há quatro níveis, sendo 1 o mais baixo e 40 mais alto. 
laboratório de ciências, laboratório de informática para alunos (com acesso à internet), pátio coberto, auditório, duas quadras de esporte (uma coberta e outra descoberta), parque infantil e área verde, sala de professores, de coordenação e de direção, almoxarifado e refeitório. Como se trata de uma construção antiga, notavam-se problemas de manutenção e de conforto ambiental, com excesso de ruído proveniente das áreas externa e interna. As salas de aula eram amplas, com possibilidades de arranjos variados (duplas, grupos, semicírculo, etc.). Havia murais na escola e no corredor central, estantes com livros e revistas para leitura de alunos e familiares. A escola localiza-se em território de vulnerabilidade alta, com IPVS 5 (SEADE, 2015).

Nessa escola, a proficiência média em língua portuguesa e matemática, em 2011, nos anos iniciais do Ensino Fundamental era, respectivamente, de 162,08 e 176,06 (INEP, 2015), abaixo da média municipal.. A taxa de reprovação, em 2014, para os anos iniciais do Ensino Fundamental, foi de $8,4 \%$, muito acima da média da rede municipal paulistana, de 2,3\%, no mesmo período (QEdu, 2015). Quanto à taxa de distorção idade-série no EF1 em 2014, apresenta o maior índice entre as escolas municipais do mesmo distrito: 9,5\%. Na ANA (2014), os alunos encontravam-se em sua maioria (66,22\%) no nível 4 de escrita. Em leitura, a maior parte encontrava-se nos níveis 2 (41,89\%) e 3 (31,08\%), médias inferiores às alcançadas na Escola $\mathrm{A}$.

Apesar da proximidade entre as unidades escolares, os resultados educacionais são mais favoráveis na Escola A. Mas vale a ressalva de que os resultados de ambas as escolas confirmam a tendência apontada pelos estudos de Ernica e Batista (2012) de que escolas pertencentes a territórios vulneráveis tendem a obter níveis de desempenho inferiores aos observados em escolas de outros territórios. Nas escolas deste estudo, a qualidade das oportunidades educacionais parece ser influenciada de modo negativo, muito provavelmente pela sobreposição de desigualdades e fragilidades na estrutura de oportunidades laborais, educativas e culturais das localidades onde estão situadas.

4. Arquitetura temporal para o processo de ensino e aprendizagem: RESULTADOS

O calendário escolar e a distribuição das aulas, do tempo para o ensino e para a alimentação e recreação estão normatizados por dispositivo legal, publicado anualmente no Diário Oficial do Município de São Paulo. Em 2014, conforme a Portaria Municipal 6.348/2013, para as turmas do ciclo de alfabetização 
estavam previstas 40 semanas de aula, com 28 horas-aula semanais, totalizando 50.400 minutos/ano, mais 80 horas-aula de enriquecimento curricular $^{18}$ de 45 minutos, o que totaliza 60.000 minutos/ano. Estabelecese para o conjunto das escolas da RMESP que no Ensino Fundamental 1 as crianças devam ter 6 horas-aula de 45 minutos por dia, 270 minutos, mais 30 minutos destinados à refeição (café e almoço ou jantar), totalizando 300 minutos/dia de permanência na escola. Essa distribuição, como se sabe, sofre ajustes anualmente, de acordo com intercorrências no âmbito da gestão municipal e escolar. A configuração oficial para o ano de 2014 foi usada como parâmetro para tecer análises sobre o emprego do tempo nas duas escolas e turmas de 30 ano.

O foco da análise recai sobre o tempo dedicado ao ensino; outras categorias de tempo são analisadas na medida em que afetam o tempo disponível para o ensino.

Tabela 1 - Emprego diário do tempo nas escolas: médias, erros padrão e intervalos de confiança

\begin{tabular}{|c|c|c|c|c|c|c|c|c|c|}
\hline \multirow{3}{*}{$\begin{array}{l}\text { Tempo (min) } \\
\text { Permanência }\end{array}$} & \multicolumn{4}{|c|}{ Escola A } & \multicolumn{4}{|c|}{ Escola B } & \multirow[b]{2}{*}{$\begin{array}{c}\text { Tempo } \\
\text { legal }\end{array}$} \\
\hline & Média & $\begin{array}{c}\text { Erro } \\
\text { padrão }\end{array}$ & \multicolumn{2}{|c|}{$\begin{array}{c}\text { Intervalo de } \\
\text { confiança }\end{array}$} & Média & $\begin{array}{c}\text { Erro } \\
\text { padrão }\end{array}$ & $\begin{array}{r}\text { Interv } \\
\text { confi }\end{array}$ & $\begin{array}{l}\text { alo de } \\
\text { ança }\end{array}$ & \\
\hline & 272 & 1,9 & 268,8 & 276,2 & 271 & 2,8 & 265,8 & 277,1 & 300 \\
\hline Morto & 29 & 2,0 & 24,6 & 32,6 & 30 & 2,8 & 24,6 & 35,8 & 0 \\
\hline Interrupção (a) & 26 & 3,1 & 19,4 & 31,9 & 33 & 3,3 & 26,1 & 39,4 & 0 \\
\hline Interrupção (b) & 1 & 0,8 & $-0,2$ & 2,9 & 2 & 0,8 & 0,2 & 3,5 & 0 \\
\hline Refeição & 33 & 1,1 & 30,6 & 34,9 & 40 & 1,1 & 37,5 & 41,9 & 30 \\
\hline Ensino & 239 & 2,1 & 234,4 & 242,9 & 230 & 2,6 & 224,8 & 235,4 & 270 \\
\hline
\end{tabular}

Fonte: Elaborado pelos autores com dados da Unifesp e do Cenpec (2017).

Nota: 0 nível de significância dos intervalos de confiança é de $5 \%$.

Com base nas observações registradas nos protocolos, foi calculado o tempo médio ${ }^{19}$ de permanência efetiva na escola para as quatro turmas do 30 ano da Escola A e para as três turmas da Escola B: 272 minutos/dia e 271 minutos/ dia, respectivamente (Tabela 2 ). Em ambas, o tempo médio de permanência é

18 Aulas que ocorrem em outros ambientes, por exemplo, no laboratório de informática e sala de leitura, e que dizem respeito a projetos da escola, desenvolvidos por docentes do Ensino Fundamental.

19 Média simples dos tempos de permanência efetiva na escola observados em todas as turmas, por escola. 
estatisticamente menor do que o estabelecido pela RMESP, de 300 minutos. Ao analisarmos os horários de entrada e saída dos alunos, verificamos que eles entram no horário oficialmente estipulado, porém saem mais cedo.

A magnitude do tempo morto é elevada nas duas escolas: cerca de meia hora diária (67\% de uma hora-aula) é perdida, tanto por conta de interrupções quanto porque os alunos não estão na escola. Os tempos das interrupções revelam falha de planejamento das aulas, pois enquanto a média das interrupções é de cerca de 30 minutos nas duas escolas, a média de tempo com eventos imprevistos é de 1 minuto na Escola $A$ e de 2 minutos na $B$. Lembrando a definição das interrupções, isso mostra que a maioria delas é composta por eventos previsíveis na rotina escolar, que, se antecipados no quadro de horários e planos de ensino, poderiam ser contornados (tais como o horário de almoço e o início e fim de aulas com professores especialistas). O tempo dedicado às refeições, que deveria ser de 30 minutos diários, é, em média, maior que isso nas duas escolas; mas vale destacar que na Escola $A$ esse tempo é bem próximo do estabelecido oficialmente.

Tendo em vista os valores das categorias de tempo já analisadas, não surpreende o fato de que as duas escolas tenham despendido em média um tempo menor com ensino que o oficial ${ }^{20}$ : na Escola A é de 239 minutos/dia, na Escola B é de 230 minutos/dia. Nas escolas A e B, as crianças do 30 ano têm, em média, quase um período de aula a menos do que o previsto por dia, principalmente porque ficam menos tempo do que deveriam na escola. Isso mostra como o tempo dedicado ao ensino varia negativamente nas duas escolas, estando suscetível às condições objetivas em que se realiza o processo educativo e ao manejo dos atores envolvidos, mesmo que integrem o mesmo sistema de ensino, que ordena racional e minuciosamente a gestão do tempo e a distribuição de aulas para o conjunto das escolas ${ }^{21}$.

As tabelas 2 e 3 trazem os tempos médios por turma, em cada escola. Constata-se que todas as turmas de $3^{\circ}$ ano têm tempos de ensino inferiores ao estabelecido pela RMESP. Em todas as turmas, o tempo de permanência é menor que o oficial e o tempo morto é significativamente diferente de zero: todos os alunos de $3^{\circ}$ ano saem mais cedo que o horário previsto,

20 Para o cálculo do tempo dedicado ao ensino, para cada observação, somaram-se os tempos de atividades de língua portuguesa, atividades das demais disciplinas, abertura espaço-temporal, fechamento espaço-temporal. Ou seja, não foram considerados os tempos de refeições, nem tempos mortos. Foi calculada uma média simples desses tempos das turmas por escola.

${ }^{21}$ Portarias Municipais 6.348/2013 e 6.340/2013. 
independentemente da turma ou do professor. Todas as turmas das duas escolas têm tempos de interrupção estatisticamente positivos, indicando que há falhas de planejamento por não se considerar o almoço ou outras aulas com especialistas na gestão das atividades na rotina diária.

Tabela 2 - Emprego diário do tempo por turmas da Escola A: médias, erros padrão e intervalos de confiança

\begin{tabular}{|c|c|c|c|c|c|c|c|}
\hline & Tempo (min) & Permanência & Morto & Interrupção (A) & Interrupção (B) & Refeição & Ensino \\
\hline \multirow{4}{*}{$\frac{\mathbb{1}}{\text { 을 }}$} & Média & 274 & 28 & 29 & 3 & 33 & 239 \\
\hline & Erro padrão & 2,61 & 3,83 & 5,48 & 2,50 & 1,53 & 4,63 \\
\hline & \multirow{2}{*}{ Int. de confiança } & 268,14 & 20,09 & 17,52 & $-3,00$ & 29,62 & 228,72 \\
\hline & & 279,43 & 36,63 & 41,20 & 8,00 & 36,24 & 248,71 \\
\hline \multirow{4}{*}{ 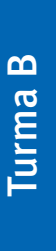 } & Média & 270 & 31 & 21 & 2 & 31 & 237 \\
\hline & Erro padrão & 4,88 & 4,81 & 5,14 & 0,98 & 2,91 & 4,85 \\
\hline & \multirow{2}{*}{ Int. de confiança } & 259,20 & 21,15 & 9,51 & $-0,63$ & 24,97 & 226,92 \\
\hline & & 280,13 & 41,79 & 31,56 & 3,72 & 37,43 & 247,74 \\
\hline \multirow{4}{*}{ 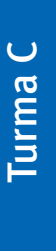 } & Média & 276 & 24 & 34 & 0 & 35 & 241 \\
\hline & Erro padrão & 1,60 & 1,60 & 6,42 & - & 1,42 & 2,49 \\
\hline & & 272,98 & 20,06 & 19,79 & - & 32,06 & 235,88 \\
\hline & Int. ae connalnça & 279,94 & 27,02 & 47,75 & - & 38,24 & 246,74 \\
\hline \multirow{4}{*}{ 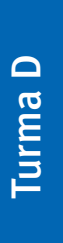 } & Média & 271 & 30 & 20 & 2 & 32 & 238 \\
\hline & Erro padrão & 4,40 & 4,42 & 7,46 & 1,60 & 2,34 & 4,53 \\
\hline & Int de confianca & 261,22 & 20,91 & 4,40 & $-2,02$ & 27,05 & 227,81 \\
\hline & IIIt. ae commança & 280,11 & 39,89 & 36,40 & 5,22 & 37,08 & 247,26 \\
\hline
\end{tabular}

Fonte: Elaborado pelos autores com dados da Unifesp e do Cenpec (2017).

Nota: O nível de significância dos intervalos de confiança é de $5 \%$.

Quanto ao tempo gasto com refeição, na Escola $B$ todas as turmas têm um tempo médio superior a 30 minutos. Na Escola $A$, somente na turma $C_{0}$ tempo médio ultrapassa 30 minutos - o que explica a proximidade do tempo médio de refeição da escola ao oficialmente estabelecido. Destaca-se que na distribuição de tempos pela RMESP não está contabilizado o tempo de transição entre atividades, tampouco os deslocamentos para quadras de esporte e salas de leitura, por exemplo. Por consequência, parece inevitável certo afastamento das recomendações oficiais. Nossa hipótese para este é que, na Escola $A$, haveria um controle maior desse momento e em relação ao deslocamento das turmas entre a sala de aula e o refeitório, partilhado entre professores e agentes escolares, responsáveis pelas crianças nessas ocasiões. 
Tabela 3 - Emprego diário do tempo por turmas da Escola B: médias, erros padrão e intervalos de confiança

\begin{tabular}{|c|c|c|c|c|c|c|c|}
\hline \multicolumn{2}{|c|}{ Tempo (min) } & Permanência & Morto & Interrupção (A) & Interrupção (B) & Refeição & Ensino \\
\hline \multirow{4}{*}{ 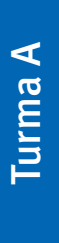 } & Média & 275 & 25 & 43 & 0 & 39 & 236 \\
\hline & Erro padrão & 5,06 & 5,06 & 6,53 & - & 1,97 & 4,11 \\
\hline & Int. de & 263,27 & 14,18 & 28,36 & - & 34,62 & 226,39 \\
\hline & confiança & 285,82 & 36,73 & 57,45 & - & 43,38 & 244,70 \\
\hline \multirow{4}{*}{$\begin{array}{l}\infty \\
\stackrel{\infty}{E} \\
\underline{\underline{E}} \\
\underline{\underline{E}}\end{array}$} & Média & 266 & 36 & 32 & 2 & 42 & 222 \\
\hline & Erro padrão & 5,11 & 5,07 & 5,25 & 1,17 & 1,44 & 4,52 \\
\hline & Int. de & 254,65 & 25,52 & 20,40 & $-0,25$ & 38,92 & 211,90 \\
\hline & confiança & 276,55 & 47,28 & 42,93 & 4,86 & 45,08 & 231,30 \\
\hline \multirow{4}{*}{ 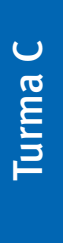 } & Média & 275 & 27 & 26 & 3 & 38 & 235 \\
\hline & Erro padrão & 4,20 & 3,92 & 5,05 & 1,98 & 2,22 & 3,99 \\
\hline & Int. de & 266,21 & 18,88 & 15,09 & $-1,47$ & 32,99 & 226,23 \\
\hline & confiança & 284,36 & 35,83 & 36,91 & 7,16 & 42,59 & 243,48 \\
\hline
\end{tabular}

Fonte: Elaborado pelos autores com dados da Unifesp e do Cenpec (2017).

Nota: O nível de significância dos intervalos de confiança é de $5 \%$.

Até aqui comparamos os tempos médios das escolas com os tempos oficialmente fixados pela RMESP. A partir de agora, vamos fazer comparações entre as escolas e entre as turmas da mesma escola ${ }^{22}$. A Escola A despende um tempo estatisticamente maior com ensino que a Escola $B$; e esta última despende um tempo estatisticamente maior com as refeições do que aquela. Para os demais tempos (permanência efetiva e morto), as diferenças verificadas não são estatisticamente significativas (Tabela 4).

22 Para comparar as escolas e as turmas dentro de cada escola, usamos o teste não paramétrico de igualdade de medianas de Mann-Whitney. Isso se justifica por dois motivos: a amostra de observações por escola é pequena - a Escola A tem 57 observações/dia e a B tem 40 - e a mediana é uma medida mais robusta que a média para distribuições assimétricas. Os tempos investigados não têm distribuição normal pelo teste de normalidade de Shapiro-Wilk. A medida de assimetria indica que temos distribuições assimétricas. Todos os cálculos foram feitos no Stata 14.2. Não foram reportados os testes de Mann-Whitney por turmas. Os resultados podem ser solicitados aos autores. 
Tabela 4 - Teste de Mann-Whitney para a igualdade de medianas das escolas

\begin{tabular}{cc|c|} 
Tempo & \multicolumn{1}{c}{$\begin{array}{c}\text { Estatística } \\
\text { do teste }\end{array}$} & P-valor \\
Refeição & $-4,781$ & 0,000 \\
\hline Permanência na escola & $-0,796$ & 0,426 \\
Ensino & 2,765 & 0,006 \\
Morto & 0,374 & 0,708 \\
\hline
\end{tabular}

Fonte: Elaborado pelos autores com dados da Unifesp e do Cenpec (2017).

$\mathrm{Na}$ Escola A, os resultados relativos ao tempo dedicado ao ensino não diferem entre turmas. Isso pode indicar maior controle ou planejamento por parte da equipe de gestão e docentes no que tange à maximização do tempo atribuído às aulas. Já na Escola $B$, constata-se que as turmas $A$ e $C$ desfrutam de maior tempo de ensino do que a turma B. Esta turma também está em desvantagem com respeito ao tempo morto, que é maior quando comparado com o da turma $A$.

Há ainda, por parte da RMESP²3, a determinação de horas-aula por disciplina, como mostra o Quadro 1. Observa-se que no ciclo de alfabetização quase um quarto das horas-aula (315 minutos) semanais deve ser destinado ao ensino de língua portuguesa. Para os outros componentes, exceto matemática, deve ser destinado um tempo menor. Tomando a recomendação da RMESP, para cumprir a carga horária semanal, em média, o tempo de ensino diário de língua portuguesa deveria ser de 63 minutos. Nas duas escolas, a média de tempo diário destinado a essa disciplina é de 96 minutos, estatisticamente superior ao oficialmente estabelecido. Vale mencionar que as escolas não diferem entre si quanto ao tempo dedicado ao ensino de língua portuguesa; também não há diferenças entre as turmas de cada escola.

Quadro 1 - Distribuição de carga horária por disciplina

\begin{tabular}{lc|c|}
\multicolumn{1}{c}{$\begin{array}{c}\text { Componentes } \\
\text { curriculares }\end{array}$} & $\begin{array}{c}\text { Horas-aula } \\
\text { semana }\end{array}$ & \multicolumn{1}{c}{$\begin{array}{c}\text { Percentual } \\
\text { por disciplina }\end{array}$} \\
Língua Portuguesa & 7 & 23,33 \\
Matemática & 7 & 23,33 \\
Ciências & 3 & 10 \\
Geografia & 3 & 10 \\
História & 3 & 10 \\
Educação Física & 2 & 6,66 \\
\hline
\end{tabular}

${ }^{23}$ Portaria municipal 6.340/2013: institui as Matrizes Curriculares para todas as etapas da Educação Básica da RMESP. 


\begin{tabular}{|l|c|c|}
\hline $\begin{array}{l}\text { Língua Estrangeira } \\
\text { Moderna }\end{array}$ & 2 & 6,66 \\
\hline $\begin{array}{l}\text { Sala de leitura } \\
\text { Informática }\end{array}$ & 1 & 3,33 \\
\hline Artes & 1 & 3,33 \\
\hline Total & 30 & 3,33 \\
\hline
\end{tabular}

Fonte: Elaborado pelos autores com base na Portaria Municipal 6.340/2013.

A arquitetura temporal de ambas as escolas consagra mais tempo ao ensino de língua portuguesa e isso pode ser interpretado de várias formas. Uma justificativa para essa atribuição diz respeito ao ciclo de alfabetização: este é o período em que conhecimentos e capacidades devem ser consolidados e todas as crianças, alfabetizadas. Apesar de atribuir tempo análogo à alfabetização, encontrar-se no mesmo território e com alunos de origem socioeconômica semelhante, as escolas diferem em níveis de proficiência na ANA. Na Escola A, observam-se resultados mais satisfatórios que na Escola B, quando comparadas à média municipal. Em leitura, a RMESP concentra maior percentual de alunos no nível 3, assim como a Escola A, que supera a média municipal em 4 pontos percentuais. Já a Escola $B$ concentra maior percentual de alunos no nível 2 em relação à média municipal, superando-a em 13 pontos percentuais. Em escrita, na RMESP há maior concentração de alunos no nível 4; o mesmo comportamento é observado nas escolas A e B, com a diferença que a primeira supera em 4 pontos percentuais a média municipal e a média da segunda. Quando se observam os resultados obtidos na etapa final dos anos iniciais do Ensino Fundamental, as médias de proficiência de ambas as escolas permanecem abaixo da municipal. A distribuição de tempo para o ensino de língua portuguesa seria uma reação da escola aos resultados apresentados nas avaliações estandardizadas, como a Prova Brasil? A atribuição de um tempo maior para consolidação da alfabetização pode ser visto, nessa perspectiva, como de caráter preventivo. Seria uma estratégia intencional para alfabetizar crianças com baixo capital cultural, habitantes de territórios vulneráveis e de origem socioeconômica desfavorecida? Ou seria uma forma de lidar com as diversas demandas de conteúdos e expectativas de aprendizagem que se colocam para a alfabetização nos dias atuais? Essas hipóteses nos levam a refletir sobre a qualidade das ocasiões destinadas ao ensino, isto é, quanto se mostram adequadas aos conteúdos a serem ensinados e às necessidades formativas do conjunto dos alunos dessas escolas ${ }^{24}$.

24 Sobre a qualidade das oportunidades educacionais na alfabetização, Marcucci (2015), Fonseca (2016) e outros pesquisadores têm se empenhado para configurá-la em ambas 


\section{CONSIDERAÇÕES FINAIS}

Carroll (1984) afirma que a aprendizagem é resultado da soma do tempo atribuído à aprendizagem e do tempo que o aluno necessita para dominar determinado conteúdo ou desenvolver certas capacidades. Nesse sentido, quando se focaliza a equidade nas oportunidades educativas, a oferta de ocasiões para todos os alunos aprenderem, a arquitetura temporal que se produz a partir da escola torna-se uma faceta importante a ser considerada. E especificamente para escolas que atendem crianças que interagem com as desvantagens de habitar territórios socialmente vulneráveis (o que interfere diretamente em suas experiências escolares), o emprego do tempo e sua maximização, não apenas da quantidade, mas também - e sobretudo - da qualidade do tempo dedicado ao ensino, precisam ser considerados. A partir dessa proposição, perguntamo-nos: os alunos das escolas participantes deste estudo dispõem de ocasiões para aprender similares àquelas previstas para todos os alunos matriculados na RMESP?

Os resultados revelam dissemelhanças entre os tempos previstos oficialmente e a arquitetura temporal gestada no interior de ambas as escolas. Diariamente, os alunos matriculados nessas escolas perdem 30 minutos do tempo destinado às aulas porque saem mais cedo do que o estabelecido e por conta de interrupções. Ambas, portanto, distanciam-se diante do estabelecido pela RMESP. Corroborando esses resultados, Crahay (2002) afirma que a variabilidade é inerente ao processo educativo, seja em sistemas de ensino mais centralizados, como é o caso em tela, seja naqueles descentralizados, e que as determinações legais influenciam apenas parcialmente a realidade das salas de aula, como vimos nos resultados de ambas as escolas.

O tempo menor de permanência do que o previsto, como se demonstrou, interfere naquele atribuído ao ensino, o que permite algumas reflexões. Se por um lado, os estudos sobre a arquitetura temporal em escolas de território vulnerável podem indicar desigualdades no interior de sistemas de ensino, por outro, não permitem identificar desigualdades no tratamento de conteúdos visados nos currículos. Em outras palavras, a investigação sobre a distribuição do tempo escolar não é suficiente para tecer compreensões sobre o que as crianças aprendem ou não, dado que ocasiões de aprender língua portuguesa lhes são oferecidas em proporção até maior do que a recomendada. Tais resultados evidenciam um dos problemas discutidos por Crahay (2002): o tempo dedicado ao ensino é um indicador de equidade, mas 
pouco revela sobre o que se ensina e como se ensina, o que diz respeito, justamente, à dimensão da qualidade da oferta educacional.

Outra constatação diz respeito à diferença no tempo atribuído a cada turma no interior de uma mesma escola. A Escola A emprega maior tempo para o ensino e observa-se uma distribuição semelhante para o conjunto das quatro turmas de $3^{0}$ ano. Também é a escola que obtém melhores resultados nas avaliações estandardizadas, o que pode relacionar-se com a preocupação perante o tempo atribuído às aulas. A Escola $B$, por sua vez, apresenta média inferior em relação ao tempo de ensino e ainda dissemelhanças entre turmas: nas turmas A e C, as crianças desfrutam de maior tempo dedicado ao ensino do que as da turma $B$, que apresenta média maior de tempo morto. Este parece um elemento a ser considerado para a melhoria da qualidade das oportunidades educacionais e incremento de aprendizados nesta escola.

Os resultados também apontam para uma diferença entre as escolas quanto à gestão do tempo reservado às refeições. Na Escola B, o tempo atribuído ao café e ao almoço ultrapassa o recomendado, interferindo no tempo atribuído às aulas. Na Escola $A$, há um manejo que se coloca a favor do ensino; uma estratégia que extrapola a ação docente, já que envolve outros atores da escola.

A arquitetura temporal da aula é suscetível ao manejo do professor, especialmente quando se observa o tempo das interrupções previsíveis. Se tais momentos estão previstos na rotina, seria necessário planejar o uso do tempo, sem as descontinuidades observadas. Essa possibilidade leva à reflexão sobre o peso da autonomia desses atores no que tange à manipulação dos tempos a favor dos alunos. Trata-se, como afirma Crahay (2002), de um grande dilema. Se focalizarmos os direitos educativos dos alunos, verificaremos que certos grupos não têm as mesmas oportunidades de ensino como pressuposto oficialmente. Se focalizarmos as condições objetivas a que estão submetidas escolas de território vulnerável, é preciso considerar que estas interferem sobremaneira no modo como o conjunto dos atores compreende a função da instituição, lida com os papéis que ali desempenham e com a forma escolar, o que pode levá-los a não perceber outros modos de organização do trabalho ou a resistir às imposições de um modelo único e, por vezes, pouco conhecido para os alunos e seus familiares (SANT’ANNA, 2009; ERNICA, BATISTA, 2012).

Outro aspecto a considerar é a formação dos professores, a fim de compreender as implicações da gestão do tempo para o ensino, especialmente as 
consequências de sua não otimização. Nesse sentido, pode-se questionar se as políticas educacionais devem autorizar ou desautorizar modos de gestão que não beneficiam os alunos. A esse respeito concordamos com Crahay (2002, p. 256), quando afirma que, mais do que impor quadros de horários aos professores e demais atores da escola, seria mais oportuno mobilizá-los a se comprometer com metas e resultados positivos para todos os alunos. Isso impõe considerar os processos de formação continuada de professores e demais atores e a ênfase no trabalho coletivo no interior da escola, a fim de produzirem estratégias e de planejarem a prática educativa com foco na maximização do tempo de ensino. Trata-se de um tema que diz respeito à esfera de ação do conjunto de profissionais da escola e implica o estabelecimento de prioridades e consensos a fim de atender às especificidades desses estabelecimentos e às necessidades dos alunos e das famílias.

Ainda sobre os docentes, é necessário refletir sobre as condições de trabalho e carreira de profissionais que atuam em territórios que acumulam desvantagens para seus habitantes e que afetam as escolas. Políticas voltadas à valorização desses profissionais, à melhoria das condições de trabalho e plano de carreira mais atrativo podem contribuir para o recrutamento e manutenção de professores bem preparados para atuar nesses territórios, onde os desafios para a escola e para os profissionais da educação tendem a ser ainda maiores.

Porfim, se este trabalho contribui no que se refere à análise da gestão do tempo em escolas de territórios socialmente vulneráveis, problemática central tanto na distribuição de oportunidades de aprender quanto no enfrentamento das desigualdades educacionais, que reproduzem desigualdades socioespaciais, também tem limites. Sendo um estudo de natureza qualitativa, apesar de reunir constatações que mobilizam a reflexão sobre a realidade de outras escolas, seus resultados não são generalizáveis. 0 que apreendemos incita 0 estudo mais aprofundado sobre essa realidade, bem como de demais escolas inseridas em territórios similares. 


\section{Time management and learning opportunities in the metropolis of São Paulo: analyzing two schools situated in vulnerable territories}

Abstract: It is analyzed here the temporal structure of two municipal public schools situated in socially vulnerable territories, one of the facets related to equity in education. The qualitative study, with ethnographic inspiration, was focused on the third grade of elementary school. It was focused on time management in the face of legal resolutions, specifically the one assigned to Portuguese Language classes and teaching. Results show differences in the face of what was established by that municipal teaching network, denoting inequality of educational opportunities. Having in mind what literature indicates about school knowledge dissemination, where students coming from more disfavored areas are disadvantaged, time management tends to be crucial both in opportunities distribution so that all can reach established learnings as in facing educational inequalities, that propagate socio-spatial inequalities,

Key words: Time management. Education in vulnerable territories. Educational opportunities. Equality. 


\section{Gestión del tiempo y oportunidades de aprendizaje en la metrópoli de São Paulo: un análisis de dos escuelas ubicadas en territorios vulnerables}

Resumen: Se analiza la arquitectura temporal de dos escuelas públicas municipales paulistanas ubicadas en territorio socialmente vulnerable, una de las facetas relativas a la equidad en la educación. El estudio cualitativo, con inspiración etnográfica, se detuvo en grupos del tercer año de la Enseñanza Básica de estas escuelas. Se centró en el manejo del tiempo ante las disposiciones legales, específicamente en el ámbito asignado a las clases y a la enseñanza de la Lengua Portuguesa. Los resultados señalan disimilitudes frente a lo establecido por esa red municipal de enseñanza, lo que denota desigualdad en la distribución de oportunidades educativas. Llevando en cuenta lo que la literatura señala sobre la distribución del conocimiento escolar, según la cual los alumnos provenientes de medios desfavorecidos poseen desventajas, la gestión del tiempo tiende a ser fundamental tanto en la distribución de oportunidades para que todos realicen los aprendizajes establecidos cuanto respecto al enfrentamiento de las desigualdades educacionales, que reproducen desigualdades socioespaciales.

Palabras-clave: Gestión del Tiempo. Educación en Territorios Vulnerables. Oportunidades Educacionales. Equidad. 


\section{REFERÊNCIAS}

BATISTA, Antônio; CARVALHO-SILVA, Hamilton. Família, escola, território vulnerável. São Paulo: Cenpec, 2013. Disponível em: http://www.cenpec.org. br/wp-content/uploads/2015/09/Fam\%C3\%ADlia-Escola-Territ\%C3\%B3rioVulner\%C3\%A1vel.pdf

BONDIOLI, A.; MANTOVANI, S. Manual de educação infantil: de 0 a 3 anos. Porto Alegre: Artmed, 2002.

BOURDIEU, P. Efeitos do lugar. In: BOURDIEU, P. (org.). Miséria do mundo. Petrópolis: Vozes, 1997. p. 159-166.

BOURDIEU, P. Os três estados do capital cultural. In: BOURDIEU, P. Escritos de educação. 4. ed. Petrópolis: Vozes, 1998. p. 71-79.

BRASIL. Talis: pesquisa internacional sobre ensino e aprendizagem: relatório nacional. Brasília: Inep: MEC, 2014.

BRESSOUX, P. As pesquisas sobre o efeito-escola e o efeito-professor. Educação em Revista, Belo Horizonte, n. 38, p. 17-88, dez. 2003.

BROOKE, N.; SOARES, J. F. Pesquisa em eficácia escolar: origem e trajetórias. Belo Horizonte: Editora da UFMG, 2008.

CAROLL, J. B. A model of school learning: progress of an idea. In: ANDERSON, W. Time and school learning: theory, research and practice. Londres: Croom Helm, 1984. p. 15-45.

CRAHAY, M. Poderá a escola ser justa e eficaz? Da igualdade das oportunidades à igualdade dos conhecimentos. São Paulo: Instituto Piaget, 2002.

DUBET, F. 0 que é uma escola justa? A escola das oportunidades. São Paulo: Cortez, 2008.

ELIAS, N. Sobre o tempo. Rio de Janeiro: Jorge Zahar, 1998.

ERNICA, M.; BATISTA, A. A. G. A escola, a metrópole e a vizinhança vulnerável. Cadernos de Pesquisa, v. 42, n. 146, p. 640-666, maio/ago. 2012.

ESCOLANO, A. Tiempo y educación. La formación del cronosistema: horario en la escuela elementar (1825-1931). Revista de Educación, n. 301, p. 127-163, 1993. 
FONSECA, G. L. da. Produção textual: o que se ensina em turmas de $3^{\circ}$ ano em escolas localizadas em territórios com alta vulnerabilidade? 2016. Dissertação (Mestrado) - Universidade Federal de São Paulo, Guarulhos, 2016.

FUNDAÇÃO SEADE. Índice Paulista de Vulnerabilidade Social. Disponível em: http://www.seade.gov.br/indice-paulista-de-vulnerabilidade-social-ipvsversao-2010/. Acesso em: 20 out. 2015.

INSTITUTO NACIONAL DE ESTUDOS E PESQUISAS EDUCACIONAIS ANÍSIO TEIXEIRA (INEP). Ideb Escola. 2015. Disponível em: http://idebescola.inep. gov.br/ideb/escola/dadosEscola/35055591\#graficocomparacao. Acesso em: 20 out. 2014.

KAZTMAN, R. Seducidos y abandonados: el aislamiento social de los pobres urbanos. Revista de la Cepal, n. 75, p. 171-189, dez. 2001.

MARCUCCI, F. A educação nas grandes metrópoles: ensino de língua portuguesa em São Miguel Paulista. 2015. Dissertação (Mestrado) - Universidade Federal de São Paulo, Guarulhos, 2015.

MARTINIC, S. El tiempo y el aprendizaje escolar: la experiencia de la extensión de la jornada escolar en Chile. Revista Brasileira de Educação, v. 20, n. 61, abr./jun. 2015. Disponível em: http://www.scielo.br/pdf/rbedu/v20n61/14132478-rbedu-20-61-0479.pdf. Acesso em: 6 abr. 2015.

MARTINIC, S.; VERGARA, C.; HUEPE, D. Uso del tiempo e interacciones en la sala de clases: un estudio de casos en Chile. Pro-Posições, Campinas, v. 24, n. 1, abr. 2013. Disponível em http://www.scielo.br/scielo.php?cript=sci_artt ext\&pid=S010373072013000100009\&lng=en\&nrm=iso. Acesso em: 15 ago 2013.

MATÊNCIO, M. L. M. Estudo da língua falada e aula de língua materna: uma abordagem processual da interação professor/alunos. Campinas: Mercado de Letras, 2001.

NÓVOA, A. Os professores e sua formação. Lisboa: Dom Quixote, 1992.

QEdu. [online] Disponível em: http://www.qedu.org.br/. Acesso em: out. 2015.

RIBEIRO, L. C. de Q. Proximidade territorial e distância social: reflexões sobre o efeito de lugar a partir de um enclave urbano. VeraCidade, Salvador, v. 3, n. 3, p. 1-21, maio 2008. 
RIBEIRO, V. M. Justiça na escola e regulação institucional em redes de ensino do estado de São Paulo. 2012. Tese (Doutorado) - Universidade de São Paulo, São Paulo, 2012.

SACRISTÁN, G. 0 aluno como invenção. Porto Alegre: Artmed, 2005.

SAMMONS, P. As características-chave das escolas eficazes. In: BROOKE, N.; SOARES, J. F. Pesquisa em eficácia escolar: origem e trajetórias. Belo Horizonte: Editora da UFMG, 2008. p. 335-382.

SANT'ANNA, M. J. O papel do território na configuração das oportunidades educativas: efeito escola e efeito vizinhança. In: CERNEIRO, S. de S.; SANT'ANNA, M. J. Cidades, olhares, trajetórias. Rio de Janeiro: Garamond, 2009. p. 167-192.

SÃO PAULO (Município). Portaria n. 6.448, de 14 de outubro de 2013. Diário Oficial do Município, Poder Executivo, São Paulo, 15 out. 2013.

SÃO PAULO (Município). Portaria Municipal n. 6.340, de 6 de novembro de 2013. Diário Oficial do Município. Poder Executivo, São Paulo, 6 nov. 2013. Disponível em: http://www3.prefeitura.sp.gov.br/cadlem/secretarias/ negocios_juridicos/cadlem/integra.asp?alt=07112013P\%20063402013SME. Acesso em: 20 out. 2016.

TEIXEIRA, I. A. de C. Tempos enredados: teias da condição professor. 1998. Tese (Doutorado) - Universidade Federal de Minas Gerais, Belo Horizonte, 1998.

VICENT, G.; LAHIRE, B.; THIN, C. Sobre a história e a teoria da forma escolar. Educação em Revista, Belo Horizonte, n. 33, p. 7-47, 2001.

VIÑAO FRAGO, A. La distribución del tiempo y del trabajo en la enseñanza primaria en España (1900-1936). Historia de la Educación, n. 16, p. 113-131, 1997.

YOUNG, M. Superando a crise na teoria do currículo: uma abordagem baseada no conhecimento. Cadernos Cenpec - Nova série, [s.l.], v. 3, n. 2, set. 2014. Disponível em: http://cadernos.cenpec.org.br/cadernos/index.php/ cadernos/article/view/238/249. Acesso em: 26 jul. 2017. DOl http://dx.doi. org/10.18676/cadernoscenpec.v3i2.238. 


\section{SOBRE AS AUTORAS:}

Fernanda Marcucci é mestre em Ciências pela Universidade Federal de São Paulo (Unifesp) e doutoranda em Educação e Saúde na Infância e Adolescência pela mesma universidade. E-mail: fernanda.marcucci@gmail.com

Claudia Lemos Vóvio é doutora em Linguística Aplicada pela Universidade Estadual de Campinas. Atua como professora associada do Departamento de Educação e Coordenadora do Programa de Pós Graduação em Educação e Saúde na Infância e Adolescência da Unifesp. E-mail: claudiavovio@gmail.com

Paula Reis Kasmirski é doutoranda em Economia pela Escola de Economia de São Paulo da Fundação Getúlio Vargas (FGV). Foi pesquisadora do Cenpec entre 2013 e 2016. E-mail: prkasmirski@gmail.com

Hivy Damasio Araújo Mello é doutora em Sociologia pela Universidade Estadual de Campinas. Realiza pós-doutoramento na mesma universidade. Foi pesquisadora do Cenpec entre 2014 e 2017. E-mail:hivy_mello@gmail.com

Recebido em: abril de 2019

Aceito em: abril de 2019 